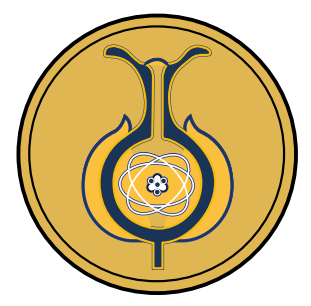

\title{
Gestión del riesgo de desastres: Competencias para una nueva cultura hidroambiental
}

\author{
Disaster risk management: competencies for a new hydro-environmental \\ culture
}
Gestão de riscos de desastres: Competências para uma nova cultura hidroambiental

Jeannette Arauz Muñoz ${ }^{1}$, Cristian Moreira Segura ${ }^{2}$, Claudia Charpentier Esquivel ${ }^{3}$, Gustavo Barrantes Castillo ${ }^{4}$

Received: Mar/29/2021 • Accepted: Jun/25/2021 • Published: Jan/31/2022

\section{Resumen (10)}

El propósito del estudio fue elaborar y validar competencias, metodologías y recursos didácticos para una nueva cultura hidroambiental en la gestión del riesgo de desastres en estudiantes y docentes costarricenses de II ciclo de la Escuela Excelencia Cahuita, Limón. La investigación se desarrolló con un enfoque cualitativo de carácter interpretativo y propositivo donde participaron nueve expertos nacionales e internacionales ( 3 en gestión de riesgos de desastres (grupo 1), 3 en cambio climático (grupo 2 ) y 3 en educación (grupo 3 ) a través de la aplicación del método Delphi que constó de 3 fases: preparatoria, consulta y consenso. Los resultados indican que los grupos 1 y 2 elaboraron 43 competencias para luego validar diez por cada grupo, el grupo 1 distribuyó las competencias en conceptuales, internas y externas, el grupo 2 solo competencias cognitivas, tanto para los niños como para los maestros, tomando en cuenta indicadores, recursos didácticos y metodologías. En la fase 3, el grupo 3, ajustó y validó las competencias elaboradas por los grupos 1 y 2 que consisten en 20 competencias, y una serie de recursos y metodologías. Se concluye que las competencias son un aporte que garantizará, en la medida de su práctica, una mejor preparación ante eventos de vulnerabilidad y riesgo causados por el cambio climático. El material educativo de referencia podría ajustarse para otras regiones de Costa Rica y de Latinoamérica.

Palabras clave: Competencias; valores; alfabetización ambiental; riesgos climáticos; desastres; metodologías didácticas, cambio climático; adaptación.

\footnotetext{
Jeannette Arauz Muñoz, \jeannettearauz@gmail.com, (D): https://orcid.org/0000-0002-9867-6855

Cristian Moreira Segura, $\$ cmoreira@itcr.ac.cr, (D: https://orcid.org/0000-0003-3047-2415

Claudia Charpentier Esquivel, \ ccharpen@gmail.com, (D: https://orcid.org/0000-0003-3525-9664

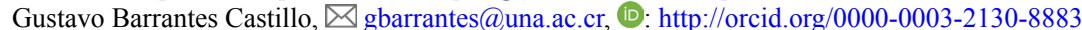

1 Doctorado en Ciencias Naturales para el Desarrollo (DOCINADE), Instituto Tecnológico de Costa Rica, Universidad Nacional, Universidad Estatal a Distancia, Costa Rica.

2 Instituto Tecnológico de Costa Rica, Programa de Doctorado en Ciencias Naturales para el Desarrollo. Costa Rica.

3 Universidad Nacional, Costa Rica.

4 Escuela de Ciencias Geográficas, Universidad Nacional, Costa Rica.
} 


\section{Abstract (AD)}

The study was aimed to develop and validate competencies, methodologies, and teaching resources for a new hydro-environmental culture in disaster risk management for Costa Rican students and teachers of the second cycle of the Cahuita Excelencia Elementary School in Limón. The research was developed under an interpretive and propositional qualitative approach with the participation of nine national and international experts (3 in Disaster Risk Management [Group 1], 3 in Climate Change [Group 2], and 3 in Education [Group 3]), using the Delphi method which consisted of 3 phases: preparation, consultation, and consensus. Results indicate that Groups 1 and 2 developed 43 competencies, of which ten were validated by each group. Group 1 distributed competencies into conceptual, internal, and external, while Group 2 only distributed cognitive competencies, both for children and teachers, taking into account indicators, didactic resources, and methodologies. During Phase 3, Group 3 adjusted and validated the competencies developed by Groups 1 and 2, which consist of 20 competencies and a series of resources and methodologies. It is concluded that competencies will contribute to guarantee better preparation for vulnerability and risk events caused by climate change. The reference educational material could be adjusted to other regions of Costa Rica and Latin America.

Keywords: Competencies; values; environmental literacy; climate risks; disasters; didactic methodologies; climate change; adaptation.

\section{Resumo}

Este estudo teve como objetivo desenvolver e validar competências, metodologias e recursos didáticos para uma nova cultura hidroambiental na gestão de riscos de desastres em estudantes e docentes da Costa Rica do II ciclo da Escola de Excelência Cahuita, Limón. A pesquisa foi desenvolvida com uma abordagem qualitativa de caráter interpretativo e proposital, onde participaram nove especialistas nacionais e internacionais (3 em gestão de risco de desastres (grupo 1), 3 em mudanças climáticas (grupo 2) e 3 na educação (grupo 3) através da aplicação do método Delphi que consistiu em 3 fases: preparatória, consulta e consenso. Os resultados indicam que os grupos 1 e 2 desenvolveram 43 competências e, em seguida, validaram dez para cada grupo, 0 grupo 1 distribuiu as competências em conceituais, internas e externas, 0 grupo 2 apenas competências cognitivas, tanto para crianças quanto para professores, levando em conta indicadores, recursos didáticos e metodologias. $\mathrm{Na}$ fase 3, 0 grupo 3 ajustou e validou as competências desenvolvidas pelos grupos 1 e 2, compostas por 20 competências, e uma série de recursos e metodologias. Conclui-se que as competências são uma contribuição que garantirá, na medida em que se pratica, uma melhor preparação para eventos de vulnerabilidade e risco causados pela mudança climática. 0 material educativo de referência poderia ser ajustado para outras regiões da Costa Rica e da América Latina.

Palavras-chave: Competências; valores; alfabetização ambiental; riscos climáticos; desastres; metodologias didáticas, mudança climática; adaptação. 


\section{Introducción}

El personal docente en la actualidad tiene un rol básico en la educación ambiental; este es facilitar, a la comunidad socioeducativa, información para la comprensión de los procesos ambientales dentro del contexto al que pertenecen, para que conozcan y valoren la biodiversidad (Ordóñez, Montes \& Garzón, 2018; Salas, 2021), los espacios ambientales variados relacionados con las diferencias que existen a escalas geográficas, fenómenos meteorológicos, el calentamiento global y los recursos hídricos (Arauz, Moreira \& Charpentier, 2020), de manera que puedan tomar decisiones informadas y responsables con respecto a prevenir riesgos socioambientales, proteger y conservar el medio ambiente.

Los países de América Latina y el Caribe (ALC) pertenecen a una región que está en constante amenaza de diferentes desastres como inundaciones, huracanes, sequías y terremotos, eventos que han venido en aumento (Fundación DARA Internacional, 2011), situación que es expuesta en el Marco de Acción de Sendai para la Reducción del Riesgo 2015-2030, donde se plantean cuatro prioridades para fomentar la reducción y la gobernanza del riesgo de desastres. Según los reportes estadísticos de Emergency Events Database EM DAT, durante las décadas de los años 60 y 70 se registraron menos de veinte desastres; luego durante los años 2000 hasta nuestros días la media aumentó a 50 desastres por año, aunque se han vuelto menos peligrosos resultan más costosos por los daños que producen a su paso (Ashwill \& Álvarez, 2014).

Dicha información es confirmada por las Naciones Unidas (2015), al señalar que las regiones de América Latina y el Caribe son particularmente vulnerables a las consecuencias del cambio climático (CC) producto de su situación geográfica y climática, su condición demográfica, socioeconómica y su alta sensibilidad al clima, realidad que, unida a los fenómenos naturales históricos, eleva las condiciones de riesgo a desastres que impactan de manera negativa el bienestar de las personas, la conservación de los recursos naturales y el desarrollo económico de la región (Capacci, \& Mangano, 2015).

Educar para contrarrestar la problemática del CC implica ir en contra de la principal amenaza del presente desde la perspectiva ambiental denominada calentamiento global (CG), la cual es provocada por la actividad humana desarrollada en el planeta que produce numerosos cambios ambientales (Soto, 2015), los cuales desatan desastres en comunidades y limitan el desarrollo sostenible (DS). Debido a lo anterior, la gestión del riesgo de desastres (GRD) es primordial dentro de la dimensión educativa para incidir en la investigación e intervención de la formación de los educandos y el resto de las personas, y promover el cambio de la cultura energética centrada en el conocimiento, la comprensión y la actuación dirigida hacia una colectividad baja en carbono (Heras, 2015), así como la construcción de competencias, dentro del currículo, que posibilite confrontar situaciones adversas constituyendo una ecociudadanía (González, Meira y Gutiérrez, 2020).

Costa Rica, debido a sus condiciones geológicas y geográficas, se caracteriza por ser un país multiamenaza y no está exenta de las afectaciones producto del CG. A pesar de esfuerzos efectuados en política pública, como la Política Nacional de Adaptación al Cambio Climático 2018-2030 MINAE (2018), el Plan Nacional de Descarbonización (2019), la Contribución Nacionalmente 
Determinada (2020), la Política Nacional de Gestión del Riesgo 2016-2030, la Estrategia de Gestión del Riesgo en el Sector Educación 2019-2021, el Plan Nacional de Gestión del Riesgo 2021-2025, entre otros, y de acciones del sector privado, todavía existe una brecha entre el deber ser con el hacer sobre la correspondencia entre la GRD y el $\mathrm{CC}$ en el sistema educativo formal.

Con base en lo anterior, se considera necesario hacerle frente a la crisis del $\mathrm{CC}$ que requiere el fomento de la sostenibilidad ambiental por medio de la GRD, desde el contexto escolar. La incorporación de conocimientos sobre los riesgos climáticos centrados en la GRD y el CC en la educación ambiental (EA), a través estrategias pedagógicas y didácticas que permitan conformar una sociedad ambientalmente alfabetizada obedece a que, tanto docentes como estudiantes son piezas claves; los primeros como agentes difusores de competencias y los segundos como dinamizadores del conocimiento (Galaz, Fuentealba, Cornejo, \& Padilla, 2014).

Por lo tanto, es determinante un enfoque de competencias para la acción (Álvarez, Sureda \& Comas, 2018; Finn \& Karsten, 2010; Hollweg, Taylor, Bybee, Marcinkowski, McBeth \& Zoido, 2011), que contribuya en el proceso de formación de una nueva cultura hidroclimática de prevención del riesgo y resiliencia que procure aportar al conocimiento de la realidad nacional. Por lo que un grupo de expertos elaborarán y validarán competencias para una nueva cultura hidroambiental en la GRD en estudiantes y docentes costarricenses, teniendo en cuenta contenidos, estrategias metodológicas y recursos que serán empleados por el personal docente y niños del II Ciclo para la enseñanza de la GRD relacionadas con el CC, y que formará parte de una propuesta educativa.
El término competencias se caracteriza por ser una expresión de carácter académico, científico, político y educativo, con gran cantidad de investigaciones que evidencian una amplia bibliografía con diferentes definiciones, usos y enfoques (conductismo, funcionalismo, constructivismo y el sistémico-complejo), así como la falta de una teoría unificada (Mulder, Weigel \& Co1lins, 2006; Rychen \& Salganik, 2003; Tobón, 2007; Roegiers, 2016). Así pues, por su carácter "complejo" (Schneckenberg, 2008) y "polisémico" (Díaz Barriga, 2011), no hay hoy una conceptualización unívoca sino una definición pragmática y "multidimensional" (Mulder et al., 2006). Al mismo tiempo, las contribuciones para su desarrollo resultan de diferentes campos de investigación, como la psicología, la administración, la ingeniería, la tecnología y la educación, entre otros.

Dentro de este contexto e independientemente del enfoque del pensamiento o definición de competencias que el ámbito educativo asuma, todas coinciden con tres propuestas (Roegiers, 2016): 1) El contenido de la enseñanza sobrepasa el saber o conocimiento teórico y el saber hacer; se dirige más bien hacia las life skills o competencias para la vida basadas en capacidades transversales. 2) La función protagonista del educando en el aprendizaje y el de mediador del docente. 3) La carga axiológica del saber actuar en determinadas situaciones problemáticas y complejas requiere de varios saberes para su resolución, conocimientos (conceptual), capacidades (internas) y saber hacer (externas). Es decir, los saberes necesitan ponerse en práctica y requieren de "una acción personal de compromiso para desarrollar una determinada competencia en un determinado contexto social" (García, 2011, p. 5). 
Las potencialidades que posee el estudiantado (cognitivo, sensorio-motriz, socio-afectivo) son componentes esenciales de las competencias, las cuales son consideradas más como un enfoque educativo que un modelo pedagógico en donde se da la integración de saberes: saber ser, el saber hacer, el saber conocer y el saber convivir, y puede realizarse "desde cualquiera de los modelos pedagógicos existentes" (Tobón, 2007). Y según Díaz Barriga (2011), dado que no existe el enfoque de competencias en la educación, es perentorio definir desde cuál perspectiva teórica se las aborda.

En este sentido, el modelo marco de trabajo o acción para la alfabetización ambiental (MAAA) propuesto por la NAAEE (Hollweg et al, 2011) se desarrolla con dos enfoques de pensamiento: el complejo, en donde según Tobón (2007), las competencias son "procesos de desempeño complejos ante problemas y actividades con idoneidad y ética, buscando la actuación personal, el desarrollo social y económico sostenible, el equilibrio con el ambiente, calidad de vida" (p. 20). Y con el enfoque "socioconstructivista" que reconoce el rol del estudiante en la construcción de su conocimiento partiendo de sus conocimientos previos, la importancia del contexto del aprendizaje (aprendizaje situado), es decir, con base en situaciones de la vida real y la importancia de los niveles de desempeño o etapas de desarrollo de las competencias establecidas gradualmente (Díaz Barriga, 2011).

Dentro de este modelo, una persona alfabetizada ambientalmente (Hollweg et al., 2011; Marušić Jablanović, 2020) será aquella que, ya sea de manera individual como en grupo, es consciente en la toma de decisiones sobre el medio ambiente; además está dispuesta a actuar sobre estas decisiones para mejorar el bienestar de otros individuos, las sociedades y el medio ambiente mundial participando en la vida cívica. De manera que el modelo MAAA de la NAAEE promueve una nueva cultura ambiental entre estudiantes. La cultura ambiental la refiere Gabriel Campos (2016) como "aquella actitud, posición y comportamiento ante la vida que permite preservar y cuidar nuestro ambiente, lo que resulta un motivo de interés para la comunidad, familia o escuela, es decir para todo el mundo" (p. 140).

En el contexto de Costa Rica, por sus condiciones geográficas y climatológicas, los niños y docentes deben estar preparados y formados desde competencias conceptuales, internas y externas dentro de una educación para el desarrollo sustentable (EDS) (Rieckmann, 2019; Wiek, Withycombe y Redman, 2011), que les permitan actuar de manera responsable sobre su medioambiente. El docente actual debe manejar y desarrollar en los estudiantes una nueva cultura hidroambiental de prevención del riesgo y resiliencia que procure el aporte de conocimientos de la realidad local y nacional, a través de prácticas innovadoras de enseñanza aprendizaje que los oriente a fortalecerla. Para el logro de la nueva cultura hidroambiental se deben incorporar cambios en la estructura de la formación, metodologías, recursos bibliográficos y en los contenidos que guíen el cómo se deben manejar las situaciones de riesgo producidas por el CC.

Son evidentes los peligros producidos por el clima en los cuales está expuesta la población y los sistemas naturales, por lo que se debe seguir una ruta hacia el DS: educar para el manejo, la mitigación y adaptación ante el desastre en zonas con altos niveles de calentamiento, desarrollo desigual y vulnerabilidad. De allí que se requiere que se elaboren y validen un conjunto de 
competencias que faciliten a los docentes y niños el cumplimiento de la Agenda 2030 para el DS, que tiene entre sus principales objetivos vincular las políticas de transformación productiva con los imperativos del cuidado ambiental (Comisión Económica para América Latina y el Caribe, 2016, Convención Marco de las Naciones Unidas sobre el Cambio Climático, 2016). Dentro de este orden, el objetivo del estudio que aquí se describe fue elaborar y validar competencias, metodologías y recursos didácticos para una nueva cultura hidroambiental en la gestión de riesgo de desastres asociadas al cambio climático en estudiantes y docentes del II Ciclo en la escuela Excelencia Cahuita (EEC), Limón, Costa Rica.

\section{Metodología}

Se efectuó un estudio cualitativo (Hernández, Fernández, \& Baptista, 2014), de carácter interpretativo y propositivo. La obtención de la información se realizó mediante la aplicación del método Delphi (García-Ruiz \& Lena-Acebo, 2018; Ortega, 2008), en un proceso interactivo de consulta a expertos que permitió construir y validar competencias teniendo en cuenta los contenidos curriculares, recursos didácticos y metodologías apropiadas que posibilitan el fomento y desarrollo de habilidades, destrezas y disposición ambiental (Sureda, Oliver, Catalan \& Comas, 2014), en los educandos y docentes, que serán posteriormente utilizadas para la formulación de una propuesta educativa ambiental para la EEC.

El empleo del método Delphi no especifica la cantidad de números de expertos, solo sugiere una cantidad, esta va a depender de los aspectos como la diversidad de los colectivos, el ámbito geográfico y las áreas específicas de desempeño de estos mismos. Es uno de los métodos más empleados en los estudios científicos en contextos problemáticos que comprende la identificación de los contenidos hasta la construcción de instrumentos de análisis, recogida de información para llegar a un consenso (Cabero e Infante, 2014).

Como parte de un protocolo elaborado previamente para realizar la consulta, se hizo la selección de expertos nacionales e internacionales escogidos de manera intencional, distribuidos en 3 grupos Delphi: el primero en gestión de riesgo de desastres (GD1), el segundo en cambio climático (GD2), y el tercero por educadores (GD3). En cada grupo participaron 3 expertos, con edades comprendidas entre 40 a 60 años. Su aplicación implicó el desarrollo metodológico planificado de acciones y tareas sucesivas cuyo cumplimiento riguroso repercute en la calidad y obtención de los resultados (García \& Suárez, 2013). A continuación, se presenta en la Tabla 1, el protocolo que cumplió el estudio que comprendió tres fases. 
Tabla 1. Fases del estudio

\begin{tabular}{lll}
\hline I. Fase preparatoria & II. Fase de consulta & III. Fase de consenso \\
\hline 1) Selección de los expertos. & 4) Realización de las rondas de consulta. & 7) Construcción del \\
2) Preparación de los instrumen- & 5) Procesamiento estadístico sucesivo. & consenso. \\
tos y anexos que fueron someti- & P (\%)=F*N.100 & 8) Reporte de resulta- \\
dos a la consideración de los & F= Frecuencia & \\
expertos. & N= Número total de F. & \\
3) Decisión de la vía de consulta. & $\begin{array}{l}\text { 6) Retroalimentación de los resultados del } \\
\text { procesamiento de las respuestas. }\end{array}$ & \\
\hline
\end{tabular}

${ }^{a}$ Los anexos fueron: Un glosario con las definiciones asumidas por la investigación; el documento de la contextualización geográfica y de riesgos del distrito tercero de Cahuita, Talamanca, Limón, Costa Rica, y los programas de estudios vigentes de I y II ciclo de Ciencias, Estudios Sociales y Educación Cívica del Ministerio de Educación Pública (MEP).

Nota: Fuente propia de la investigación.

\section{Fase I. Preparatoria}

Para la selección de expertos se utilizó el biograma del experto (Cabero y Barroso, 2013; Robles \& del Carmen, 2015), ubicado en la Tabla 2, en el que, a modo de informe, se recogió información sobre su perfil profesional y campos de estudios. Los criterios específicos que se consideraron para la selección de los expertos fueron los siguientes: 1. Grado académico igual o mayor a la licenciatura en alguna o varias disciplinas de ciencias sociales o ciencias naturales. 2. Al menos tres publicaciones en las áreas de $\mathrm{CC}$, educación, educación ambiental y GRD. 3. Trabajo probado en educación, GRD, CC, ayuda humanitaria y emergencias en agencias, escuelas, instituciones académicas, entidades públicas o privadas, ONG, y que fuera reconocido como "experto" o "especialista" en su entidad o entre sus colegas. 4. Estar actualmente trabajando en temas de sensibilización y educación, sobre GRD y CC.

Tabla 2. Resumen de objetivos y expertos consultados

\begin{tabular}{ll}
\hline Objetivo de la validación & $\begin{array}{l}\text { Elaborar competencias sobre GRD asociadas con el CC para estudiantes y } \\
\text { docentes. } \\
\text { Validar competencias, metodologías y recursos didácticos sobre GRD asocia- } \\
\text { das con el CC para estudiantes y docentes. }\end{array}$ \\
\hline $\begin{array}{l}\text { Expertos nacionales e } \\
\text { internacionales }\end{array}$ & $\begin{array}{l}\text { Ingeniería química y sanitaria, proyectos ambientales; administración de } \\
\text { empresas municipal; geografía, GRD, adaptación al CC, gestión territorial, } \\
\text { planificación áreas protegidas; meteorología y CC; ingeniería hidrológica, } \\
\text { educación ambiental, currículo; psicología, educación primaria y estudios } \\
\text { sociales, con más de } 5 \text { años de experiencia. }\end{array}$ \\
\hline Modo de validación & $\begin{array}{l}\text { Método Delphi de varias rondas: 4 para los GD 1 y GD2, y tres rondas para } \\
\text { el GD3, de forma individual y con comunicación entre el grupo de expertos } \\
\text { consultados. }\end{array}$ \\
\hline
\end{tabular}

Nota: Fuente propia de la investigación. 
Se prepararon los instrumentos en formato Microsoft Word y la validación de los cuestionarios se hizo mediante la técnica de grupo de expertos (Arribas, 2004). Se diseñaron tomando en cuenta la revisión bibliográfica y la identificación de los aspectos fundamentales que caracterizan la GRD y el CC (adaptación y mitigación) (Tabla 3 ). Luego fueron sometidos a consideración de los expertos; se enviaron trece cuestionarios diseñados con el programa Limesurvey, el cual es una herramienta tecnológica para realizar encuestas en línea. La aplicación de los cuestionarios en línea tuvo un tiempo de duración de 6 meses, en función a 4 rondas.
Cada instrumento de recolección de información constó de 4 preguntas relacionadas con las competencias necesarias para formar y fomentar en los niños de II Ciclo escolar (VI, V y VI) en la EEC para gestionar el riesgo de desastres y aumentar la resiliencia concreta de la vida personal y social producto de los efectos derivados del CC y que conduzcan hacia una nueva cultura ambiental hidroclimática. Una vez devueltas las encuestas con los archivos en formato Microsoft Excel, generados automáticamente por el programa LimeSurvey, se realizó el análisis por medio de matrices mediante el agrupamiento, simplificación y

Tabla 3. Distribución de aspectos fundamentales que comprenden los cuestionarios sobre $G R D$ relacionados con el CC (adaptación y mitigación)

\begin{tabular}{l} 
Competencias \\
\hline Internas (socioafectivas) \\
Conceptuales \\
(cognitivas-internas) \\
Externas (sensorio-motriz)
\end{tabular}

Metodologías

Actividades pedagógicas planificadas por los docentes.

Actividades pedagógicas a realizar por los niños. Acciones que deben hacer los niños.

¿Cómo?, ¿cuándo?, ¿dónde? y ¿con qué ejecutará la acción el niño?

Evaluación e indicadores de desempeño.

\begin{tabular}{l}
\hline Contenidos \\
\hline Conocimiento del clima y del ciclo del agua. \\
Diferencia de variabilidad y cambio climático en su \\
región. \\
Principales amenazas hidro-meteorológicas que existen \\
en la zona. \\
Clima y la hidrología de la región para definir las zonas \\
de riesgo de inundación. \\
Factores de vulnerabilidad y exposición que pueden \\
exacerbar y reducir el riesgo climático. \\
Ordenamiento territorial. \\
Gestión integrada del recurso hídrico. \\
Manejo de cuencas. \\
Resiliencia, cambio climático (adaptación y mitigación). \\
Zonas costeras que se verán impactadas por el aumento \\
en el nivel del mar y la erosión. \\
Factores antropogénicos, oceanológicos, geológicos, \\
planetarios. \\
Sitios afectados por crecientes y deslizamientos, sequías \\
o terremotos en la zona. \\
Desarrollo sostenible. \\
\hline Recursos didácticos \\
\hline Impreso \\
Audiovisual \\
Informático
\end{tabular}

Nota: Fuente propia de la investigación. 
parafraseo en algunos casos de cada una de las respuestas y se elaboró un documento resumen general que reunió los aportes expertos externados con apoyo en la teoría de las competencias ambientales de la NAAEE y de la taxonomía de objetivos educativos de Marzano \& Kendall (2007); se agruparon y sistematizaron por tipo de competencias generales (conocimientos, habilidades/ destrezas y disposición ambiental) y por nivel o contexto (individual, familiar y comunitaria) y escala local, regional y global.

Posteriormente, los miembros de ambos grupos recibieron la sistematización de la primera ronda de preguntas para que pudieran contestar el siguiente cuestionario de la segunda ronda, tercera y cuarta ronda. Seguidamente, la segunda fase se centró en la realización de las rondas de consulta, procesamiento estadístico sucesivo y retroalimentación de los resultados del procesamiento de las respuestas. El procesamiento estadístico tuvo la finalidad de seleccionar las competencias con más consenso, y se empleó la fórmula de porcentajes para registrar las frecuencias de las competencias más importantes a tener en cuenta en la formación de los niños y docentes en relación con la gestión de riesgo de desastres y conocimientos de los efectos derivados del CC.

\section{Fase II. Consulta}

\section{Resultados y análisis de la información}

Durante la consulta, los expertos del grupo Delphi 1, 2 y 3 aplicaron, de forma personal y anónima, varios cuestionarios estructurados con varias preguntas abiertas y cerradas de respuesta obligatoria en 3 y 4 rondas de preguntas, para un total de 24 encuestas aplicadas y respondidas. La suma total de encuestas respondidas por los tres grupos Delphi fue de 33 con un $100 \%$ de encuestas respondidas (Tabla 4).

Tabla 4. Cuestionarios elaborados y aplicados durante las rondas de preguntas a los expertos mediante el método Delphi

\begin{tabular}{|c|c|c|c|c|c|c|c|}
\hline \multirow{2}{*}{$\begin{array}{l}\text { Grupos } \\
\text { Delphi }\end{array}$} & \multirow{2}{*}{$\begin{array}{l}\text { Número } \\
\text { de ex- } \\
\text { pertos }\end{array}$} & \multirow{2}{*}{$\begin{array}{l}\text { Encuestas } \\
\text { diseñadas con } \\
\text { Limesurvey }\end{array}$} & \multicolumn{4}{|c|}{ Aplicaciones individuales } & \multirow{2}{*}{$\begin{array}{l}\text { Total } \\
\text { encuestas } \\
\text { respondidas }\end{array}$} \\
\hline & & & $\begin{array}{l}1 .^{\text {ra }} \text { ronda } \\
6 / 04 / 20\end{array}$ & $\begin{array}{l}2 .{ }^{\text {da }} \text { ronda } \\
16 / 04 / 20\end{array}$ & $\begin{array}{l}3 \cdot^{\mathrm{ra}} \text { ronda } \\
22 / 4 / 20\end{array}$ & $\begin{array}{l}4 .^{\text {ta }} \text { ronda } \\
27 / 4 / 20\end{array}$ & \\
\hline $\begin{array}{l}\text { 1ro. Gestión } \\
\text { de riesgos de } \\
\text { desastre }\end{array}$ & 3 & 4 & 3 & 3 & 3 & 3 & 12 \\
\hline $\begin{array}{l}\text { 2do. Cambio } \\
\text { climático }\end{array}$ & 3 & 4 & 3 & 3 & 3 & 3 & 12 \\
\hline \multirow[t]{2}{*}{$\begin{array}{l}\text { 3ro. Edu- } \\
\text { cación }\end{array}$} & 3 & $5^{(\mathrm{a})}$ & $4 / 05 / 20$ & $10 / 05 / 20$ & $13 / 07 / 20$ & & \\
\hline & & & 3 & 3 & $3^{(\mathrm{a})}$ & -- & 9 \\
\hline Total & 9 & 13 & 9 & 9 & 9 & 6 & 33 \\
\hline
\end{tabular}

(a) Cuestionarios personalizados para cada experto por año escolar $\left(4 .^{\text {to }}, 5 .^{\text {to }}\right.$ y $\left.6 .^{\text {to }}\right)$.

Nota: Fuente propia de la investigación. 


\section{Primera ronda}

Luego de confeccionar el primer cuestionario que constó de 5 ítems, administrado de manera online, se les preguntó a los expertos lo siguiente: ¿Cuáles competencias se deben formar y fomentar en los niños de II ciclo escolar (IV, V y VI año) en la escuela costera Excelencia Cahuita para gestionar el riesgo de desastres y aumentar la resiliencia ante situaciones concretas de la vida personal y social, producto de los efectos derivados del cambio climático (mitigación y adaptación) que pueden afectar esa región del país y que conduzcan hacia una nueva cultura ambiental hidroclimática?

De la sistematización de la información recopilada se obtuvieron un total de 43 competencias recomendadas por ambos grupos, de las cuales 15 eran del GD1 y 28 del GD2; de las relaciones entre las competencias identificadas por los expertos en
GRD y el CC (mitigación y adaptación), se sistematizó e identificó un listado de 8 competencias; 4 internas y 4 externas, y 7 conceptuales de las 15 competencias (GD1), y 28 competencias conceptuales del GD2 que más favorecían el fomento de un cambio de comportamiento para la acción ambiental y aumento de la resiliencia en los niños. De las 15 competencias del grupo GD1, cuatro de ellas representan un moderado porcentaje de competencias internas o socioafectivas (solidaridad, compromiso, respeto y adaptabilidad), mientras que las competencias externas sensorio motriz (integración, participación, aprendizaje y comunidad) reflejan igualmente un moderado porcentaje, y el resto de las competencias son conceptuales destinadas al desarrollo cognitivo, que reflejan el mayor porcentaje de todas las competencias mencionadas (Figura 1).

\section{Competencias GD1 Expertos en} GRD

1. Solidaridad. ${ }^{a}$

2. Compromiso. ${ }^{\mathrm{a}}$

3. Respeto. ${ }^{\mathrm{a}}$

4. Adaptabilidad. ${ }^{\text {a }}$

5. Integración. ${ }^{\mathrm{b}}$

6. Participación. ${ }^{b}$

7. Aprendizaje. ${ }^{b}$

8. Identificar conceptos asociados a su realidad comunitaria. ${ }^{b}$

9. Identificar y reducir los riesgos en la escuela y casa. ${ }^{c}$

10. Proponer acciones de preparación y respuesta.

11. Promover (intrafamiliar) la gestión del conocimiento y preparación. ${ }^{\mathrm{c}}$

12. Conocimiento suficientemente detallado de las condiciones materiales y sociales que caracterizan el entorno inmediato del niño, así como de la región y el país en que viven. $^{\mathrm{c}}$

\section{Competencias GD2 Expertos en CC}

1. Conocimiento del clima y del ciclo del agua.

2. Conocimiento de su entorno $(v$. g. clima como componente dinámico del planeta Tierra).

3. Conocer los vocablos de "clima" (términos de precipitación, temperatura, viento, humedad relativa, etc.) y su relación con los desastres.

4. Conocimiento de las fluctuaciones del clima.

5. Diferenciar los conceptos de variabilidad y CC en su región.

6. Comprender la relación entre la comprensión del tiempo, la distribución espacial del recurso hídrico, tanto en ecosistemas dulceacuícolas como marino-costeros, y su intrínseca fragilidad
7. Conocimiento del clima y la hidrología de la región y su relación con las zonas de desastres, además el estado de la cuenca (conocimiento de las características fisiográficas y de cobertura de ésta).

8. Conocimiento de los factores antropogénicos, oceanológicos y geológicos que alteran el clima.

9. Desarrollar la curiosidad sobre su entorno y el sentido de orientación espacial que viene de conocer su entorno y sus características.

10. Comprender la relación entre diversidad biológica y diversidad cultural de los pobladores. 11. Geo-alfabetizar a la población escolar de la zona para mejorar la gestión del riesgo y la resiliencia. 12. Percibir los factores de vulnerabilidad y exposición que pueden exacerbar y reducir el riesgo climático. 
13. Conocimiento de los conceptos de amenaza y exposición con un enfoque proactivo que permita comprender la situación de riesgo, pero también que el riesgo es manejable y que es necesario actuar de forma preventiva siempre. ${ }^{c}$

14. Internalizar la existencia de los riesgos y que estos se pueden reducir, al inducir acciones concretas que reduzcan la vulnerabilidad, que aumenten su capacidad, conociendo el fenómeno (amena$\mathrm{za}$, peligro). ${ }^{\mathrm{C}}$

15. Trabajar con un enfoque hacia las actitudes inmediatas, las cuales se reforzarán por la experiencia, el conocimiento posterior y la especialización; es necesario un conocimiento que lleve a la acción. ${ }^{\mathrm{c}}$

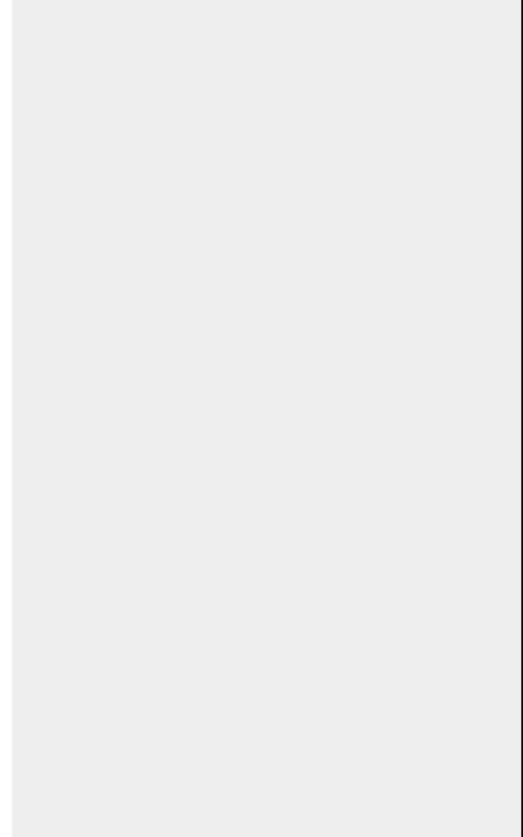

13. Conocimiento de amenazas geológicas y geomorfológicas.

14. Identificar las principales amenazas hidro-meteorológicas que existen en la zona.

15. Generar conocimientos a través de los encuentros a los centros de investigación científica y museos en donde puede brindarse información adicional al estudiante.

16. Identificar, a través de giras de campo, los sitios que han sido afectados por crecientes y deslizamientos, sequías o terremotos en la zona.

17. Mostrar en campo y concientizar los daños económicos y sociales producto de las afectaciones de crecientes y deslizamientos, sequías o terremotos en la zona. 18. Compartir las vivencias de los escolares relacionados con los efectos de daños económicos y sociales producto de las afectaciones de crecientes y deslizamientos, sequías o terremotos en la zona. 19. Geo-alfabetizar a los estudiantes sobre los deslizamientos y el azolvamiento de los ríos de la cuenca del río La Estrella, que fueron provocados por el terremoto de abril 1991, los cuales generaron también escenarios de riesgo por inundaciones con la entrada de la estación lluviosa.

20. Entender el escenario multiamenaza en el Caribe Sur requiere entender el complejo entramado entre amenazas y riesgos concatenados.
21. Percibir las zonas que se verán impactadas por el aumento en el nivel del mar y la erosión costera.

22. Conocer los términos de riesgo, mitigación y adaptación con el involucramiento de los padres de los niños con el fin de hacer mayor conciencia en la familia.

23. Conocer y valorar la importancia de qué es un plan de gestión de riesgo en su escuela y comunidad.

24. Conocer y valorar la importancia de qué es un sistema de alerta temprana (SAT) desarrollado en la zona bananera, ejemplo, Valle La Estrella. 25. Abordar, como parte de las estrategias de adaptación, la forma de hacer asentamientos humanos y desarrollo de cara a un clima menos benigno.

26. Entender las relaciones sociedad-naturaleza desde un enfoque holístico, apreciar su entorno natural, valorar la extraordinaria biodiversidad del Caribe Sur, y rescatar también la diversidad cultural y la rica historia de la zona.

27. Desarrollar los temas de ordenamiento territorial, gestión integrada del recurso hídrico y la gestión integrada de manejo de cuencas; además el estado de la cuenca (conocimiento de las características fisiográficas y de cobertura de esta que tiene un efecto directo en las crecientes).

28. Desarrollo de una buena formación en materia de geografía.

${ }^{\mathrm{a}}$ competencias internas, ${ }^{\mathrm{b}}$ competencias externas $\mathrm{y}^{\mathrm{c}}$ competencias conceptuales o cognitivas.

Figura 1. Competencias recomendadas por el GD1, Expertos en GRD y por el GD2 Expertos en $\mathrm{CC}^{\mathrm{c}}$

Nota: Fuente propia de la investigación. 
Respecto a las competencias sistematizadas e identificadas por el GD2, de las 28 se identificaron 28 conceptuales o cognitivas en su totalidad (Figura 1). Las competencias desde el enfoque del modelo de la NAAEE son generales e integrales y estas fueron relacionadas con el sistema de taxonomía de Marzano \& Kendall (2007), las cuales se tomaron en cuenta para la propuesta de los grupos Delphi 1 y 2 teniendo como referencia los verbos recomendados para indicadores y niveles cognitivos dirigidos a la construcción de competencias para una nueva cultura hidroambiental en la gestión del riesgo del desastres para los niños y docentes de la EEC.

Dentro de este marco se destaca que las competencias recomendadas por los expertos se ubican desde los niveles inferiores de complejidad cognitiva (dominio de recuperación), al proponer que el estudiante conozca información sobre el clima, los elementos del tiempo, la variabilidad climática y el CC, las amenazas hidrometeorológicas, el ciclo del agua, su entorno, entre otros conceptos, pasando por los otros niveles de la comprensión, el análisis, la aplicación y el sistema de metacognición según la clasificación de verbos para indicadores cognitivos de Marzano \& Kendall (2007). Desde la óptica del modelo de la NAAEE, las competencias propuestas se vinculan con la competencia general en donde el estudiante realiza, justifica, propone y ejecuta acciones concretas para hacer frente a los problemas ambientales relacionados con los riesgos climáticos. Esto coincide con la propuesta de habilidades del perfil educativo de II Ciclo del MEP, donde todas las competencias establecidas se vinculan con cuatro dimensiones: maneras de pensar, las nuevas formas de vivir el mundo, formas de relacionarse con otros y el uso de herramientas para integrarse al mundo (Ministerio de Educación Pública, 2016).

De esta manera, se realizó un agrupamiento por tema en GRD y CC con base en la prevención, mitigación, preparación, alerta temprana, respuesta, recuperación y reconstrucción del ciclo de la GRD, y con las estrategias de mitigación y adaptación del CC; tomando en cuenta los criterios establecidos por los expertos GD1 y 2, se agruparon en tres grupos de categorías generales: 1) Clima, variabilidad climática y CC. 2) Ciclo hidrológico e hidrología y recursos hídricos. 3) Gestión de riesgos de desastres, y dentro de este el subtema de amenazas naturales y antrópicas. Luego se efectuó un parafraseo de las opiniones y reducción de los criterios para hacer una síntesis de respuesta grupal de ambos GD 1 y 2 de los cuales se obtuvieron 17 ideas principales sobre el tema consultado.

Finalmente, un especialista del GD1 GRD señaló en línea con lo expresado por todos los expertos lo siguiente:

Experto: "es vital un abordaje común del tema de adaptación al cambio climático y gestión del riesgo, ya que son conceptos que se orientan a un mismo punto en común (el riesgo) y que artificialmente se explican como si fueran distintos. En un nivel de formación básica, lo importante es el enfoque de actitudes y visiones y para esto los fraccionamientos que pueden ser pragmáticos son contraproducentes".

\section{Competencias docentes}

En relación con las competencias que deben tener los docentes para la enseñanza de la GRD respecto del CC que conduzcan hacia una nueva cultura ambiental hidroclimática, los resultados encontrados fueron un total de 25 competencias, de las cuales 10 las estableció el GD1 GRD y 15 el GD2 CC. De esta manera, se muestran las 10 
competencias de ambos grupos de expertos que presentaron mayor concordancia, organizadas por similitud y proximidad temática en 5 bloques, se sigue la clasificación de variables del MAAA de la NAAEE: 1) Capacitación y actualización. 2) Conocimientos y propuesta de soluciones. 3) Actitud y contexto geográfico. 4) Vinculación del entorno familiar y comunal. 5) Disposiciones ambientales (Ver Anexo 1).

La GRD demanda una actualización de las metodologías docentes empleadas para fomentar cambios actitudinales en los niños. Hay evidencia científica y social de que existen cambios (mayormente provocados) en el ambiente para los que se debe estar preparado (Bello, Bustamante \& Pizarro, 2020). Por lo tanto, los docentes deben tener un alto conocimiento del marco conceptual de la GRD en relación con el CC para comprender los procesos y poderlos enseñar a los niños. Las competencias docentes surgidas están ajustadas al modelo A Rounder Sense of Purpose (RSP) y apoyadas en las competencias de la EDS (Rieckmann, 2019; Vare, Arro, De Hamer, Del Gobbo, De Vries \& Farioli, 2019), las cuales pueden ser la base de una propuesta para la formación continua, en función de mejorar sus capacidades y contribuir a la EDS.

\section{Segunda ronda}

Con las competencias propuestas por los grupos de expertos GD1 y GD2, se evaluaron las competencias a través de respuesta de acuerdo o desacuerdo, y ambos grupos estuvieron de acuerdo en la definición de estas, además de agregar otras si eran necesarias y priorizar las señaladas en la primera ronda. Las 15 competencias recomendadas por el GD1, comprenden competencias internas, externas y conceptuales. Hubo 3 competencias nuevas conceptuales, 5 competencias conceptuales, 4 competencias internas socioafectivas y 3 competencias externas sensorio motriz. Mientras que el GD2, de las 28 competencias propuestas en la primera ronda aumentó a 29 competencias conceptuales.

Aquí los expertos realizaron recomendaciones acerca de los diferentes recursos didácticos en diferente formato (impreso, audiovisual e informático) para los docentes, los niños y los padres de familia, validadas por ambos grupos. Dentro del material impreso recomiendan: plan escolar de la institución nacional rectora de gestión de riesgos, cuadernillos con información, mapa de riesgo, afiches y el plan familiar de gestión de riesgo. El recurso audiovisual: presentaciones y videos con material motivador sobre la relación naturaleza-sociedad, peligros en la casa, video animado infantil sobre la reducción de riesgo de desastres, video de la Comisión Nacional de Prevención de Riesgos y Atención de Emergencias (CNE), la Guía para la elaboración de planes de gestión del riesgo en centros educativos, el mapa de riesgos de la escuela, el video disponible en internet: ¿Conoces la diferencia entre cambio climático y variabilidad climática? Aquí te explicamos, aplicaciones, mapa de riesgos Riesgolandia, y, por último, los recursos informáticos que se proponen son: aplicaciones didácticas, libro Educación sobre CC y el ambiente, juegos, el kit ;Aprendamos a prevenir los desastres!, el juego Riesgolandia y DiscoverWater.org Usa el agua prudentemente.

Los contenidos recomendados están dentro del marco de aspectos fundamentales establecidos en la Tabla 3; entre los cuales hay relacionados con todas las competencias. Puesto que los contenidos y recursos deben estar vinculados con el nivel de conocimientos de los niños, tal como lo expresa el siguiente experto: 
Experto: "tienen que ser muy básicos empezando por el ciclo hidrológico y temas básicos de meteorología, introducción a los desastres y gestión del riesgo, es importante que el estudiante aprenda haciendo y visitando los puntos críticos donde se producen los eventos extremos. Familiarizar a los estudiantes con los elementos meteorológicos haciendo mediciones en una estación meteorológica, entre otras actividades".

Por ello, los expertos sugirieron diferentes estrategias metodológicas, técnicas didácticas y uso de recursos como: diseñar actividades específicas y recursos didácticos sobre el CC, cursos en línea, conferencias, videos, trabajo de campo, excursiones $\mathrm{y}$ visitas a los centros de investigación y museos del país, mediciones de variables climáticas empleando estaciones meteorológicas mecánicas y automatizadas, uso de material especializado editado por entes técnicos (CNE y otros organismos e instituciones relacionados con las temáticas de CC, la GRD y el recurso hídrico), y el documento Educación sobre el CC y el medio ambiente de la UNICEF.

Del listado original del total de 43 competencias identificadas por los expertos derivadas de la primera ronda, se priorizaron 10 por cada grupo. La información se analizó y agrupó para simplificar las que estaban repetidas y seleccionar las de mayor puntaje. Por cada grupo Delphi se obtuvieron 10 competencias consideradas prioritarias por los expertos para que los niños gestionen el riesgo de desastre y aumenten la resiliencia ante situaciones concretas de la vida personal por los efectos derivados del CC (adaptación y mitigación) y que conduzcan hacia una nueva cultura ambiental hidroclimática.

Seguidamente, las competencias priorizadas por el GD1 disminuyeron de 15 a 10 , tomando en cuenta las competencias internas, externas, conceptuales y nuevas; se obtuvieron 10 competencias, de las cuales una representa las competencias externas sensorio motriz, seguida de cuatro competencias internas socioafectivas, cuatro competencias conceptuales y una competencia nueva orientada hacia el desarrollo cognitivo. De este modo, el GD 2 priorizó las competencias conceptuales, organizándolas en orden de prioridad, cuya primera ronda eran 28 , reduciéndolas a 10 competencias conceptuales o cognitivas, que representan la totalidad de las competencias.

Tomando en consideración el modelo de la NAAEE, el componente disposiciones ambientales para la EA está referido hacia las competencias internas, es decir, a los aspectos actitudinales y responden al ejercicio de los valores como principios rectores y reguladores del comportamiento de los estudiantes. De acuerdo con las competencias priorizadas por los expertos, hay varias de estas que se derivaron como valores: el respeto, la solidaridad, el compromiso, la integración, la participación, la responsabilidad y la adaptabilidad. Los seis últimos podrían asociarse con la "intención de actuar" definida por Hollweg et al., (2011), y en acuerdo con lo expresado por Chuquisengo, Pinedo, Torres y Rengifo, (2005), que las asumen también como competencias porque los valores son "fundamento de la acción" (p. 4).

En este sentido, cabe resaltar que, aparte de la necesaria capacidad de conocimiento, comprensión e identificación de las situaciones de amenaza, vulnerabilidad y riesgo frente al calentamiento global y el $\mathrm{CC}$, es primordial, ante todo, el desarrollo de valores afines para la propuesta y justificación de acciones para enfrentar situaciones socioambientales derivadas de estas problemáticas. Asimismo, desde la perspectiva del Ministerio de Educación Pública, 
el eje de valores se tiene como el único eje transversal en el currículo nacional con el objetivo de que su práctica sistemática contribuya a potencializar el desarrollo social y afectivo de los estudiantes en unión con el tema transversal de la cultura ambiental para el desarrollo sostenible (MEP, 2016). Así mismo se propusieron indicadores establecidos por los dos grupos de expertos junto a cada una de las competencias priorizadas y validadas, los cuales servirán para realizar la evaluación del desempeño o logro de la competencia, estos varían según la competencia a lograr, expresadas por el número, porcentajes y evidencia de la acción.

\section{Tercera ronda}

Esta fase consistió en presentar las competencias necesarias para la acción ambiental en los niños, estas fueron priorizadas y validadas con el mayor puntaje obtenido para posteriormente ser seleccionadas; las competencias priorizadas y validadas por el GD1, resultaron: 4 competencias internas, 1 competencia externa, 4 competencias conceptuales y 1 competencia nueva, conservan la misma cantidad de competencias de la ronda dos. Por otro lado, las competencias priorizadas y validadas por el GD2 se mantienen con 10 competencias conceptuales.

Seguidamente se registró el componente conocimientos que comprenden la teoría que promueve las acciones ambientales necesarias, a su vez se muestran los indicadores y también los conocimientos como unidades que permiten estimar las acciones, tal como se muestra en las Figuras 2 y 3 . Es pertinente destacar que ninguno de los expertos en esta ronda recomendó ningún material bibliográfico en específico; no obstante, señalaron que se deben tomar en cuenta la consulta de bibliografías desarrolladas por la Federación de la Cruz Roja sobre metodologías para el abordaje comunitario para la ACC y GDR, desarrolladas específicamente para Costa Rica, lo que hace que sea más adecuada por el contexto geográfico. Así mismo, recomendaron consultar en el Centro Regional de Referencia para la Resiliencia Comunitaria de la Cruz Roja, UNICEF, UNESCO y ONG que apoyan al sector educativo.

Seguidamente, las metodologías aprobadas por ambos grupos fueron muchas. Las metodologías coinciden con las planteadas en la primera ronda a excepción de las conferencias.

\section{Cuarta ronda}

La cuarta ronda se realizó con el fin de obtener una puesta en común validada entre sí por los expertos del GD1 y GD2. Los documentos se trabajaron, simultánea e internamente en cada grupo y de manera anónima, desde la primera hasta la cuarta ronda para que fueran validados por cada grupo de manera separada y recibieran su retroalimentación en cada inicio de fase de preguntas. Fue en la cuarta ronda cuando ambos grupos, de manera intercalada, validaron los aportes del otro grupo distinto al suyo, lo que permitió una validación intergrupal de todos los aportes dados con una puesta en común. Además, durante la sistematización de la información se fueron rescatando otros aportes dados por los expertos para justificar sus ideas y que se consideraron valiosos a la luz de la teoría del modelo de la NAAEE. En la Figura 2 se muestra la validación de las competencias priorizadas y validadas propuestas por el GD1 (GRD) validadas por el GD2 (CC). Por su parte, en la Figura 3 se detalla la propuesta del GD2 (CC) con sus competencias y conocimientos priorizados y validados por el GD1 (GRD), la cual conservó el mismo orden de 
prioridad de la tercera ronda, y fueron posteriormente validadas también por los expertos en educación.

En esta ronda se incorporaron más recursos didácticos recomendados por los expertos en GRD y CC, para ser empleados por los docentes, niños y padres de familia en la formación de las competencias brindadas y validadas entre sí por ambos grupos Delphi. Uno de los aportes fue un recurso informático, el cual consistió en un enlace interactivo sobre el manejo adecuado del agua.

\section{Fase III. Consenso}

La consulta a expertos en educación (GD3) correspondió el último ejercicio de aplicación de cuestionarios. Estuvo conformada por tres rondas con aplicación de tres cuestionarios, exponiéndose y retroalimentándose los resultados del procesamiento de las respuestas emitidas por los GD1 y GD2. Los encuestados del GD3 estuvieron de acuerdo con los dos listados de las competencias priorizadas y validadas por el GD1 y GD2; sin embargo, uno de los expertos en educación realizó varios comentarios de forma para el mejoramiento en la redacción de las competencias $2,3,4,5,6,7,8$, y 10 que fueron consideradas por el grupo de expertos en GRD y validadas por el grupo de expertos en $\mathrm{CC}$ necesarios para la acción ambiental de los niños. De ello resultaron 10 competencias y conocimientos priorizados, validados con el mayor puntaje, en función del consenso entre los Grupos Delphi 1, 2, 3 (Figura 2).

\section{Competencias \\ Conocimientos \\ Indicadores}

1. Conjunto de valores. Respeto a las personas. Respeto y aprecio del entorno natural. Respeto a las leyes y reglamentos. Respetar y cuidar el entorno natural y social. Conceptos de riesgo, GRD y prevención.

1. Cantidad de planes y acciones de reducción del riesgo y ACC nivel escolar y comunitario.

2. Cantidad de factores de riesgo comunitario sobre los cuales el alumnado es capaz de identificar medidas preventivas. 3. 1 mapa (de todos los estudiantes) de riesgo de mi escuela, elaborado participativamente.

\begin{tabular}{|c|c|}
\hline $\begin{array}{l}\text { 2. Compromiso. Valoro la importancia de } \\
\text { mi compromiso personal en la iden- } \\
\text { tificación de amenazas y la reducción } \\
\text { de riesgos asociados a la variabilidad } \\
\text { climática y el cambio climático en la } \\
\text { comunidad, escuela y mi casa. }\end{array}$ & $\begin{array}{l}\text { 2. Compromiso social. } \\
\text { Desarrollo de autoestima. } \\
\text { Valores sociales. }\end{array}$ \\
\hline
\end{tabular}

3. Promuevo (intrafamiliar) la gestión del conocimiento y preparación. Promuevo a nivel de mi familia la gestión del conocimiento y acciones de preparación frente a los riesgos asociados al calentamiento global y el cambio climático.

3. Dinámicas familiares. Concepto de preparación. Acciones de preparación y respuesta. Cambio climático. Calentamiento global.
2. \# de estudiantes promueven acciones de respeto y valoro la importancia de cuidar el entorno natural y social para prevenir los riesgos de desastres. 2. \% de situaciones reales o simuladas en que el alumnado seleccionó la opción/es que refleja/n el respeto por la naturaleza. 3. 1 definición y aplicación de respeto al entorno natural.

3. \# de acciones promovidas al interior de la familia para preparación frente a los riesgos asociados al CG y el CC. 2. Cantidad de acciones familiares que resultan de la promoción realizada por el alumnado. 3. 1 video grabado de la explicación al interior de familia. 
Competencias

4. Identifico y reduzco los riesgos en la escuela y casa asociados a la realidad comunitaria y detalles del entorno que contribuyen al conocimiento, comprensión y análisis de las amenazas y la exposición a riesgos en mi escuela y casa producto del $\mathrm{CC}$, con un alto compromiso personal y social que me permita valorar la necesidad e importancia de actuar siempre de forma preventiva.

\section{Internalizo la existencia de los} riesgos y que estos se pueden reducir al practicar acciones concretas, como por ejemplo, un ejercicio de simulación para reducir la vulnerabilidad y aumentar mi capacidad conociendo la amenaza hidrometeorológica en la escuela, mi familia y mi comunidad.

6. Solidaridad. Participo de manera responsable y solidaria en las diferentes actividades y simulacros propuestos en el Plan Escolar de Gestión de Riesgos de Desastres.

\section{Conocimientos}

4. Características y análisis del entorno.

Concepto de amenazas. Identificación, comprensión y análisis de amenazas. Realidad comunitaria. Cambio climático. Compromiso personal y social.

Acción preventiva.

\section{Riesgos. Vulnerabilidad.}

Capacidad.

Fenómeno. Amenaza. Amenazas hidrometeorológicas. Peligro. Simulación. Simulacro.

\section{Indicadores}

4. \# de planes y acciones de reducción del riesgo y ACC nivel escolar y comunitario. 2. Cantidad de factores de riesgo comunitario sobre los cuales el alumnado es capaz de identificar medidas preventivas. 3. 1 mapa (de todos los estudiantes) de riesgo de mi escuela, elaborado participativamente.

5. Resultados definidos como "satisfactorios" en la participación de cada estudiante en simulaciones y simulacros. 2. 1 ejercicio de simulación (como participantes), 1 ejercicio de simulación (como organizadores).
7. Propongo acciones de preparación y respuesta. Practico en la escuela el ejercicio de simulación para aplicar los conocimientos, técnicas y recomendaciones de preparación y respuesta para resolver situaciones derivados de una de emergencia por amenazas hidrometeorológicas.

\section{Aprendizaje. Explico a mi fa-} milia la importancia de elaborar y practicar conjuntamente un plan familiar de prevención considerando las condiciones naturales y sociales del entorno.
6. Solidaridad. Simulacros. Plan Escolar de GRD. Interacción social. Acción individual.

7. Fase y acciones de respuesta. Emergencia. Simulación. Simulacro.

Fase y acciones de preparación. Amenazas hidrometeorológicas.
6. \# de estudiantes participan de manera responsable y solidaria en las diferentes actividades y simulacros propuestos en el Plan de GRD Escolar. 2. \% de acciones catalogadas como "solidarias" en una situación de emergencia que son aplicadas por estudiantes. 3. 1 documento preliminar del PGRDE.

7. Planes y acciones elaborados con estudiantes en el ejercicio de simulacro. 2. 1 Capacitación práctica (por cuerpos de socorro) en primeros auxilios básicos.

\section{Entorno natural. Entorno social. \\ Plan familiar de prevención de riesgos. \\ Fase y acciones de preparación. Fase y acciones de prevención.}

8. \# de estudiantes que promueven a lo interno de la familia la importancia de elaborar y practicar conjuntamente un plan familiar de prevención considerando las condiciones naturales y sociales del entorno. 2. Los estudiantes relatan conversaciones y experiencias familiares conversando sobre riesgo. 3. 1 Plan familiar elaborado. 
9. Rehabilitación (Competencia nueva). Analizo con mis compañeros la importancia de que la escuela cuente con un plan de continuidad de operaciones estudiantiles para ser utilizado en caso de que ocurra un desastre.
10. Adaptabilidad. Planteo soluciones a los riesgos identificados en el entorno natural sociocultural de mi comunidad para prevenir y gestionar el riesgo de desastre derivados del cambio climático.
9. Fase de rehabilitación. Plan de continuidad de operaciones.
9. Cantidad de acciones de recuperación identificadas por estudiantes. 2. 1 exposición en clase de conocimiento de los adultos mayores de la comunidad sobre desastre ocurrido.

\section{Adaptabilidad. Gestión del} riesgo de desastres. Reducción del riesgo. Entorno natural. Entorno sociocultural. Manejo de desastres. Fase de prevención. Cambio climático.
10. \# de acciones/soluciones para gestionar el riesgo de desastre derivados del cambio climático. 2. Cantidad de acciones o soluciones sobre riesgo que son planteadas por cada estudiante. 3. 1 Propuesta de solución práctica en casa para cuido del agua, como medida adaptabilidad.

Figura 2. Listado de 10 competencias, conocimientos e indicadores propuestos por el GD1 GRD priorizadas y validadas por los tres grupos de expertos producto de la consulta de la tercera ronda del GD3, necesarios para la acción ambiental de los niños.

Nota: Fuente propia de la investigación.

En el caso de las competencias y conocimientos para la acción ambiental de los niños que fueron priorizados y validados por el GD1, GD2 y GD3 se encontró que las competencias internas fueron 4 , las competencias externas muestran 1 , mientras que las competencias conceptuales reflejan $4 \mathrm{y}$ 1 competencia nueva relacionada a la parte conceptual. Por lo tanto, las competencias y conocimientos priorizados y validados por el GD2, GD1 y GD3, se mantiene con 10 competencias conceptuales (Figura 3).
Competencias

1. Conocer el clima y el ciclo del agua. Defino y distingo claramente los conceptos de clima, factores climáticos (astronómicos, geográficos y meteorológicos), elementos climáticos (radiación solar, temperatura, viento, presión, humedad, precipitación), tiempo atmosférico y ciclo del agua, reconociendo la importancia del agua en la distribución de la vida en el ambiente y su relación con el riesgo de desastres.

\section{Conocimientos}

1. Conocimiento del clima. Factores climáticos (astronómicos, geográficos y meteorológicos). Elementos climáticos (radiación solar, temperatura, viento, presión, humedad, precipitación). Tiempo atmosférico. Ciclo del agua, reconociendo la importancia del agua en la distribución de la vida en el ambiente y con la generación de desastres.

\section{Indicadores}

1. Identifica, localiza, reconoce las variables de: temperatura, humedad, lluvia, radiación solar, cobertura nubosa, velocidad y dirección de viento. 


\section{Competencias}

2. Diferencio los conceptos de clima, variabilidad climática y cambio climático y su relación con eventos meteorológicos (empujes fríos, y efecto directo de huracanes) contando con registros meteorológicos para analizar las situaciones de riesgo y desastres que impactan la región que habito.

\section{Conocimientos}

2. Temas básicos de meteorología y elementos meteorológicos. Mediciones en una estación meteorológica. Introducción a los desastres y la GRD. Desastres hidrometeorológicos. El Niño. La Niña. Vientos Alisios. Océano Pacífico Occidental y Oriental. Consecuencias de la variabilidad climática y su impacto en la calidad de vida. Atmósfera. Localización de puntos crítico donde se producen eventos extremos. Empujes fríos. Efecto directo de huracanes. Registros meteorológicos. Situaciones de riesgo y desastres de la región en donde vive el estudiante. Registro histórico de desastres.

3. Identifico las principales amenazas hidro-meteorológicas que existen en la zona que habito.

\section{Fenómenos hidrometeo-} rológicos. Afectación de los fenómenos hidrometeorológicos. Vulnerabilidad y sus factores. Exposición. Factores de exposición. Inundaciones.

\section{Indicadores}

2. Identifica, localiza, relaciona, compara, evalúa y confronta los conceptos de: Cambio climático, calentamiento global, variabilidad climática, ENOS: eventos de El Niño y La Niña, temperatura, precipitación.
3. Identifica, localiza y relaciona los conceptos de huracanes, ENOS, inundación, sequía.
4. Realizo in situ la observación meteorológica de algunas variables o elementos climáticos como la precipitación y temperatura diaria desde una estación meteorológica mecánica o digital ubicada en la escuela usando la boleta de registro para analizar y comprender el concepto de clima y su relación con la hidrología de la región en que habito y el estado físico de la cuenca que me ayude a definir las zonas de riesgo de inundación.

5. Evalúo los factores de vulnerabilidad y exposición que pueden exacerbar el riesgo climático en la región donde vivo.

\section{Hidrología de la región.} Estación meteorológica automática. Variables atmosféricas (temperatura y precipitación).

Zonas de riesgo.

Clima. Cuenca. Características fisiográficas de la cuenca. Cobertura de la cuenca. Tiempos de concentración de la cuenca. Arrastre de sedimentos. Daños a las comunidades Deforestación. Inundación.
4. Realiza, anota, mide, localiza, relaciona, compara y evalúa datos de precipitación máxima en $10 \mathrm{~min}, 20$ min, 30 min, 1 hora, 12 y 24 horas. Realizo la observación meteorológica de la variable precipitación diaria desde la estación meteorológica mecánica o digital ubicada en la escuela usando la boleta de registro que me ayude a analizar los conceptos de precipitación y el clima y su relación con la hidrología de la región en que habito y el estado de la cuenca que me ayude a definir las zonas de riesgo de inundación.

5. Identifica, evalúa las variables de temperatura, lluvia, humedad relativa. 
6. Desarrollo los conceptos de ordenamiento territorial, gestión integrada del recurso hídrico y gestión integrada de manejo de cuencas; y conozco el estado de las características fisiográficas de la cuenca y de cobertura de esta y su efecto directo en las inundaciones.
6. Ordenamiento territorial. Gestión integrada del recurso hídrico. Cuenca. Manejo de cuencas (estado de la cuenca). Características fisiográficas de la cuenca.

Cobertura de la cuenca. Inundaciones.
6. Calcula, relaciona, compara y evalúa el caudal de un río. -Medir el caudal del agua del tubo del lavamanos de la escuela para comprender cómo es el funcionamiento de la caída de lluvia en una cuenca y la relación entre la lluvia y la escorrentía y los posibles riesgos asociados a la erosión del suelo o inundaciones, entre otros.

7. Identifica, localiza, reconoce, describe, relaciona datos históricos de eventos extremos que han originado inundaciones y sequias. Analiza la climatología en meses con mayor y menor precipitación.
7. Comparto las vivencias relacionadas con los efectos de daños económicos y sociales producto de las afectaciones de inundaciones y deslizamientos, sequías o terremotos en la zona donde vivo para reflexionar sobre diferentes acciones de adaptación y mitigación que permitan aumentar la resiliencia comunitaria.

\section{Descubro las zonas que} se verán impactadas por el aumento en el nivel del mar y la erosión costera en la región donde vivo.

9. Conozco los factores antropogénicos, oceanológicos, geológicos, planetarios (tormentas solares, excentricidad, oblicuidad, modificación del balance de energía) que alteran el clima.

10. Identifico a través de giras de campo los sitios que han sido afectados por crecientes y deslizamientos, sequías o terremotos en la zona donde habito.

\section{Resiliencia. Resiliencia co-} munitaria. Conocer cómo afecta la zona el cambio climático. Adaptación y acciones de adaptación. Mitigación y acciones de mitigación. Daños económicos y sociales. Inundaciones. Deslizamientos. Sequías. Terremotos.

Figura 3. Listado de 10 competencias, conocimientos e indicadores propuestos por el GD2 CC priorizadas y validadas por los tres grupos de expertos producto de la consulta de la tercera ronda del GD3, necesarios para la acción ambiental de los niños.

Nota: Fuente propia de la investigación. 
Las metodologías validadas en consenso del GD1, GD2 y GD3 fueron producto de las observaciones y recomendaciones realizadas en las rondas tres y cuatro, con un total de 10, las cuales fueron las siguientes: 1) Diseñar actividades específicas y recursos didácticos sobre GRD y CC. 2) Cursos en línea. 3) Videos. 4) Trabajo de campo, excusiones y visitas a los centros de investigación y museos del país. 6) Mediciones de variables o elementos climáticos en la escuela empleando una estación meteorológica mecánica o automatizada. 7) Charlas temáticas por especialistas. 8) Diseño y empleo de medidores analógicos para comprender la relación analógica de lo observado con lo medido. 9) Uso de material especializado editado por entes técnicos (CNE y otros organismos e instituciones relacionados con las temáticas de CC, la GRD y el recurso hídrico). 10) Aplicaciones informáticas y juegos.

En la tercera ronda el GD3 sistematizó las competencias que deben adquirir los niños de II ciclo escolar (IV, V y VI año) y obtuvo como resultado final lo que se muestra en las Figuras 2 y 3 , dirigidas a conducir una nueva cultura ambiental hidroclimática, sistematización realizada por los GD1 y GD2 en las rondas 1, 2, 3 y 4. Una vez validadas las competencias internas, externas y conceptuales de los GD1, GD2 y GD3; paralelamente se validó el material bibliográfico, el cual resulta de gran utilidad para la construcción de la propuesta educativa centrada en la formación de competencias en los niños y docentes que facilitarán la gestión de riesgo de desastres en relación con el CC (mitigación y adaptación).

\section{Conclusiones}

La formación de competencias ambientales en el ámbito educativo es un reto mayúsculo para hacer frente a los riesgos asociados al CC actual, debido a las alteraciones complejas que han ocurrido en el entorno, producto de la intervención del ser humano. Lo anterior es así, ya que este debe estar preparado para contrarrestar y asumir situaciones de riesgos con alta incertidumbre que afecten a la sociedad, así como también aprovechar y beneficiarse de los efectos derivados del CC. Por ello se debe contar con una respuesta acorde a las actividades y estrategias educativas que se ajusten al debido manejo de escenarios de riesgo ante el desastre (CRE/UNDRR, 2019).

Este estudio demostró que en la medida que se pasaba de una ronda a la siguiente, se realimentaba, se reforzaba a través del análisis de los conocimientos de los expertos en GRD, CC y educación; se observó la pluralidad de opiniones que sirvieron de base para la conformación de las competencias. Las 20 competencias (internas, externas y conceptuales) obtenidas son una creación de la realidad desde la estimación consensuada; decisión que impactará sobre la realidad una vez puesta en práctica. El grupo de expertos en CC, GRD y educadores lograron, a través del método Delphi, la consulta y el consenso final de competencias que promoverán valores, procedimientos y capacidades cognitivos, que conjugan lo teórico y lo práctico. Se acompañan de indicadores, recursos didácticos, material bibliográfico y estrategias metodológicas que le servirán de apoyo a los docentes al momento de planificar y llevar a cabo las sesiones educativas en la EEC.

Las competencias internas (socioafectivas) y las conceptuales (cognitivas) 
dominaron, en su mayoría, en la priorización de las competencias y coincidieron con Marušić Jablanović (2020), al plantear que al contener el componente afectivo, cognitivo y procedimental se está desarrollando una alfabetización ambiental, constructo complejo que busca ir más allá de la práctica educativa. Lo anterior justifica la importancia de la definición de estas 20 competencias validadas por los tres grupos Delphi para impactar en la GRD y el CC en la EEC, pero también a nivel nacional. Sin duda, las competencias alcanzadas son un aporte que garantizará, en la medida de su práctica, menos impacto al ambiente, mejor preparación ante eventos de vulnerabilidad causados por el CC, además de que puede ser material educativo para emplearse, ajustadas a su contexto, en otras regiones de Latinoamérica. Al fomentar competencias en los estudiantes se les está fortaleciendo y desarrollando una forma renovada de ver las situaciones que transformarán sus puntos de vista para la toma de decisiones informadas y la propuesta de soluciones de los problemas ambientales.

Sin duda, es un momento crucial de cambios para los sistemas educativos, porque deben desarrollar la alfabetización ambiental, pues no es un problema regional es una situación compleja global, que hay que superar con el manejo de las habilidades, ideas, actitudes y valores que inciden en el actuar, para evitar la desaparición de los sistemas naturales y humanos. En resumen, se concluye que los logros alcanzados en el estudio contribuirán a aportar contenidos, competencias, y a generar experiencias que cultivarán el ser y el saber hacer de los estudiantes y docentes; todo ello conducente a una nueva cultura hidroambiental en la gestión del riesgo de desastres.

\section{FINANCIAMIENTO}

CeNAT-Conare, Beca de Investigación 2019.

\section{RECONOCIMIENTOS}

Al CeNAT-Conare por la beca otorgada a la primera autora del artículo; se reconoce también al Dr. Gustavo Barrantes, coordinador del proyecto interdisciplinario "Erosión Costera, Geodinámica y Gobernanza en el Caribe Sur de Costa Rica", por el apoyo brindado a la doctorante como miembro del grupo de tesistas del Programa de Geomorfología Ambiental (PROGEA) de la Escuela de Ciencias Geográficas de la UNA. Finalmente, se agradece la valiosa participación del grupo de nueve expertos que hicieron posible este estudio.

\section{DECLARACIÓN DE LA CONTRIBUCIÓN DE LOS AUTORES}

El porcentaje total de contribución para la conceptualización, preparación y corrección de este artículo fue el siguiente: J.A.M. $65 \%$, y C.C.E. $15 \%$, C.M.S $10 \%$ y G.B.C. $10 \%$.

\section{BIBLIOGRAFÍA}

Álvarez García, O; Sureda-Negre, J., \& Comas-Forgas, R. (2018). Evaluación de las competencias ambientales del profesorado de primaria en formación inicial: Estudio de caso. Enseñanza de las Ciencias, 36(1), 117-141. https://doi.org/10.5565/rev/ensciencias. 2338

Arauz Muñoz, J., Moreira Segura, C., \& Charpentier Esquivel, C. (2020). Programas de ciencias en la educación primaria costarricense: Relación entre la gestión de riesgos y el cambio climático. Revista Posgrado y Sociedad. Sistema de Estudio de Posgrado. 18(2),1-25. https://doi.org/10.22458/rpys.v18i2.2856 
Arribas, M. (2004). Diseño y validación de cuestionarios. Matronas Profesión, 5(17), 23-29.

Ashwill, M., \& Álvarez, L. (2014). Climate change and IDB: Building resilience and reducing emissions. Sector study: Disaster risk reduction. Washington. Inter-American Development Bank.

Bello, O., Bustamante, A., \& Pizarro, P. (2020). Planificación para la reducción del riesgo de desastres en el marco de la Agenda 2030 para el Desarrollo Sostenible. Documentos de Proyectos (LC/TS.2020/108), Santiago, Comisión Económica para América Latina y el Caribe (CEPAL). https://repositorio. cepal.org/bitstream/handle/11362/46001/1/ S2000453_es.pdf

Cabero Almenara, J., \& Barroso Osuna, J. (2013). La utilización del juicio de experto para la evaluación de tic: El coeficiente de competencia experta. Bordón. Revista De Pedagogía, 65(2), 25-38. https://recyt.fecyt.es/index.php/ BORDON/article/view/brp.2013.65202

Cabero Almenara, J., \& Infante Moro, A. (2014). Empleo del método Delphi y su empleo en la investigación en comunicación y educación. Edutec. Revista Electrónica De Tecnología Educativa, (48), 272. https://doi. org/10.21556/edutec.2014.48.187

Capacci, A. \& Mangano, S. (2015). Las catástrofes naturales. Cuadernos de Geografia. Revista Colombiana de Geografia, 24(2), 35-51. http://www.redalyc.org/articulo. oa? $\mathrm{id}=281839793003$

CEPAL (Comisión Económica para América Latina y el Caribe). (2016), Horizontes 2030: $\mathrm{La}$ igualdad en el centro del desarrollo sostenible (LC/G.2660/Rev.1). https://www. cepal.org/es/publicaciones/40116-horizontes-2030-la-igualdad-centro-desarrollo-sostenible-sintesis

Chuquisengo, O., Pinedo, L., Torres, A., \& Rengifo, F. (2005). Guía metodológica para la gestión de riesgos de desastres en los centros de educación primaria. ITDG AL. https://www.eird. org/cd/herramientas-recursos-educacion-gestion-riesgo/pdf/spa/doc16517/doc16517.htm

CMNUCC (Convención Marco de las Naciones Unidas sobre el Cambio Climático). (2016). Acuerdo de París. Naciones Unidas. https:// unfccc.int/sites/default/files/spanish_paris_ agreement.pdf
CRE/UNDRR (Global Assessment Report on Disaster Risk Reduction / Informe de Evaluación Global sobre la reducción de riesgos de desastres). (2019). El costo humano de los desastres: Una mirada a los últimos 20 años (2000-2019). https://www.eird.org/americas/ gar.html

Fundación DARA Internacional. (2011). Índice de reducción del riesgo (IRR) índice de reducción del riesgo en América Central y el Caribe. Análisis de capacidades y condiciones para la reducción del riesgo de desastres. https://daraint.org/

Díaz Barriga, Á. (2011). Competencias en educación. Corrientes de pensamiento e implicaciones para el currículo y el trabajo en el aula. Revista Iberoamericana de Educación Superior (RIES), 5(2), 3-24.

Finn, M., \& Karsten, S. (2010). The action competence approach and the 'new' discourses of education for sustainable development, competence and quality criteria, Environmental Education Research, 16(1), 59-74. http://doi. org/10.1080/13504620903504032

Gabriel Campos, E. (2016). Plan de gestión de riesgos de desastres y cultura ambiental: Un análisis desde el enfoque cuantitativo. Espacio Y Desarrollo, (29), 135-152. https://doi. org/10.18800/espacioydesarrollo.201701.006

Galaz, A., Fuentealba, R., Cornejo, J., \& Padilla, A. (2014). El desafío de transformar la formación docente y asegurar el cambio del modelo educacional. Estudios pedagógicos, 40, 7-10. http://dx.doi.org/10.4067/ S0718-07052014000200001

García Retana J. A. (2011). Modelo educativo basado en competencias: Importancia y necesidad. Revista Actualidades Investigativas en Educación, 11(3), 1-24. https://www.redalyc. org/pdf/447/44722178014.pdf

García Ruiz, Ma E., \& Lena Acebo, F. J. (2018). Aplicación del método Delphi en el diseño de una investigación cuantitativa sobre el fenómeno FABLAB. EMPIRIA. Revista de Metodología de Ciencias Sociales. 40, 129-166. https:// doi.org/10.5944/empiria.40.2018.22014

García Valdés, M., \& Suárez Marín, M. (2013). Empleo del método Delphi en investigaciones sobre salud publicadas en revistas científicas cubanas. Revista Cubana de Información en Ciencias de la Salud, 24(2), 
133-144. http://www.redalyc.org/articulo. oa? $\mathrm{id}=377648460004$

González Gaudiano, E. J., Meira Cartea, P. A., \& Gutiérrez Pérez, J. (2020). ¿Cómo educar sobre la complejidad de la crisis climática? Hacia un currículum de emergencia. Revista Mexicana de Investigación Educativa, 25(87), 843-872.

Heras Hernández, Francisco. (2015). La educación en tiempos de cambio climático. Facilitar el aprendizaje para construir una cultura de cuidado del clima. Mètode Science Studies Journal, 85, 57-63. https://metode.es/wp-content/ uploads/2015/05/85ES2_educacion_cambio_ climatico.pdf

Hernández Sampieri, R., Fernández-Collado, C., Baptista-Lucio, P. (2014). Metodología de la investigación (6. ${ }^{\text {ta }}$ ed.). Mc Graw Hill. Interamericana Editores.

Hollweg, K. S., Taylor, J. R., Bybee, R. W., Marcinkowski, T. J., McBeth, W. C., \& Zoido, P. (2011). Developing a framework for assessing environmental literacy. North American Association for Environmental Education.

Marušić Jablanović, M. (2020). Environmental Literacy, its Components and Significance. En Stanković, M \& Nikolić, V. (Eds.), PaKSoM2020. Conference: 2nd Virtual International Conference Path to a Knowledge Society-Managing Risks and Innovation. Proceedings. Research and Development Center "IRC ALFATEC", Niš, Serbia Complex System Research.16-17. https://www.researchgate.net/publication/348705884

Marzano, R. J., \& Kendall, J. S. (2007). The new taxonomy of educational objectives. (2. ${ }^{\mathrm{a}}$ ed.). Thousand Oaks, C. A.: Corwin Press A Sage Publications Company. California.

MINAE. (2018). Política Nacional de Adaptación al Cambio Climático 2018-2030. DECRETOS 41091-MINAE. Gaceta n. ${ }^{\circ}$ 92. Año CXL. Costa Rica.

Ministerio de Educación Pública (MEP). (2016). Programa de Ciencias. Segundo Ciclo de la Educación General Básica. Departamento de Educación Académica. San José, Costa Rica: MEP.

Mulder, M., Weigel, T., \& Collings, K. (2006). The concept in the development of vocational education and training in selected EU member states. A critical analysis. Journal of Vocational Education and Training, 59(1),65-85.
Naciones Unidas. (2015). La economía del cambio climático en América Latina y el Caribe. Paradojas y desafíos del desarrollo sostenible. Autor. http://repositorio. cepal.org/bitstream/handle/11362/37310/ S1420656_es.pdf? sequence $=4$

Ordóñez-Díaz, M., Montes-Arias, L., \& Garzón-Cortes, G. (2018). Importance of Environmental Education in Socio-Natural Risk Management in Five Countries of Latin America and the Caribbean. Revista Electrónica Educare, 22(1), 1-19. https://doi.org/10.15359/ree.221.17 en ciencias sociales. Revista EAN, (64), 31-54.

Ortega, F. (2008). El método Delphi, prospectiva.

Plan Nacional de Descarbonización 2018-2050. (2019). https:/unfccc.int/sites/default/files/ resource/Plan $\% 20 \mathrm{Nacional} \% 20 \mathrm{de} \% 20 \mathrm{Des}-$ carbonizaci\%C3\%B3n\%20-\%20Espa\%C3\%B1ol.pdf

Rieckmann, M. (2019). Competencias de educación para el desarrollo sustentable para educadores: Perspectivas de un proyecto internacional. En Memorias del seminario internacional: Educación superior basada en competencias y los objetivos del desarrollo sustentable, 8, 15-18. Publisher: Cuvellier Verlag, Göttingen. https://www.researchgate. net/publication/337534873_Competencias de_educacion_para_el_desarrollo_sustentable_para_educadores_Perspectivas_de_un proyecto internacional

Robles, P., \& del Carmen M. (2015). La validación por juicio de expertos: Dos investigaciones cualitativas en lingüística aplicada. Revista Nebrija de Lingüística Aplicada a La Enseñanza de Lenguas, (18), 103. https://www. nebrija.com/revista-linguistica/files/articulosPDF/articulo_55002aca89c37.pdf

Roegiers, X. (2016). Marco conceptual para la evaluación de competencias. Serie Cuestiones fundamentales y actuales del currículo y el aprendizaje. BE/2016/WP/CD/04. OIE-UNESCO.

Rychen, Dominique Simone and Salganik, Laura Hersh. (2003). A Holistic Model of Competence. In Rychen, Dominique Simone and Salganik, Laura Hersh (Eds.), Key Competences for a Successful Life and a Well-Functioning Society (pp. 41-62). Hogrefe \& Huber, Publishers. 
Salas López, G. (2021). Evaluación de una estrategia de educación ambiental sobre el conocimiento de la fauna nativa en el marco de la taxonomía popular. Revista Electrónica Educare, 25(1), 1-15. https://doi.org/10.15359/ ree. $25-1.2$

Schneckenberg. D. (2008). Educating Tomorrow's Knowledge Workers: The Concept of Ecompetence and Its application in international higher education. Eburon Academic Publishers. The Netherlands

Soto Ramírez, E. R. (2015). El calentamiento global y la degradación de la ozonosfera (Un análisis científico desde la diversidad de criterios). Revista Integra Educativa, 8(3), 43-54. http:// www.scielo.org.bo/scielo.php?script=sci_arttext\&pid=S1997-40432015000300004\&ln$\mathrm{g}=\mathrm{es} \& \operatorname{tln} \mathrm{g}=\mathrm{es}$

Sureda-Negre, J., Oliver-Trobat, M., Catalan-Fernández, A., \& Comas Forgas, R. (2014). Environmental education for sustainability in the curriculum of primary teacher training in Spain. International Research in Geographical and Environmental Education, 23(4), 281-293. https://doi.org/10.1080/10382046.2 014.946322 .

Tobón, S. (2007). El enfoque complejo de las competencias y el diseño curricular por ciclos propedéuticos. Acción Pedagógica, 16. 14-28.

Vare, P., G. Arro, A., de Hamer, G., Del Gobbo, G., de Vries, F.. Farioli Kadji-Beltran, K; Mayer, M.; Nijdam; \& Réti., Zachariou. (2019). Devising a competence-base., Training program for educators of sustainable development: Lessons learned. Sustainability 11(7)1890. http://doi.org/10.3390/su11071890

Wiek, A., L. Withycombe, and Redman, C. L. (2011). Key competencies in sustainability: a reference framework for academic program development. sustainability science. Sustain Sci, 6(2), 203-218. https://doi.org/10.1007/ s11625-011-0132-6

\section{(2) $(\mathbb{1} \Theta \Theta$}

Gestión del riesgo de desastres: Competencias para una nueva cultura hidroambiental (Jeannette Arauz Muñoz • Cristian Moreira Segura • Claudia Charpentier Esquivel • Gustavo Barrantes Castillo) Uniciencia is protected by Attribution-NonCommercialNoDerivs 3.0 Unported (CC BY-NC-ND 3.0) 
Anexo 1. Listado de 10 competencias docentes para la enseñanza de la GRD en relación con el CC que conducen hacia una nueva cultura ambiental hidroclimática

\begin{tabular}{|c|c|}
\hline Grupo Delphi 1 GRD & Grupo Delphi 2 CC \\
\hline \multicolumn{2}{|l|}{ 1. Capacitación y actualización } \\
\hline $\begin{array}{l}\text { 1. Refuerza y actualiza el conocimiento a través } \\
\text { de la capacitación de cursos, postgrados, mae- } \\
\text { strías y otros. }\end{array}$ & $\begin{array}{l}\text { 1. Aprende y practica una mejora continua con } \\
\text { nuevos métodos de enseñanza sobre la GRD rel- } \\
\text { ación con el CC para fomentar cambios actitudi- } \\
\text { nales en estudiantes. }\end{array}$ \\
\hline \multicolumn{2}{|l|}{ 2. Conocimientos y propuesta de soluciones } \\
\hline $\begin{array}{l}\text { 2. Tiene un manejo adecuado del marco concep- } \\
\text { tual de la GRD en relación con el CC, lo cual les } \\
\text { permitirá a sus estudiantes una capacidad educati- } \\
\text { va más exitosa. }\end{array}$ & $\begin{array}{l}\text { 2. Domina los conceptos de tiempo y clima y } \\
\text { variabilidad y CC, especialmente entiende por } \\
\text { qué se producen (cuáles son los gases efecto } \\
\text { invernadero, el ciclo del carbono, causas del } \\
\text { calentamiento, etc.). }\end{array}$ \\
\hline
\end{tabular}

\section{Actitud y contexto geográfico}

3. Transmite una visión proactiva y de responsabilidad con el entorno y con la sociedad.

3. Evalúa la percepción del entorno como parte del enfoque de la GRD en relación con el cambio climático.

\section{Vinculación del entorno familiar y comunal}

4. Desarrolla actividades vinculadas a la realidad escolar y familiar.

4. Valora la ubicación geográfica en donde se emplaza la comunidad educativa para la enseñanza de la GRD en relación con el CC.

\section{Disposiciones ambientales}

5. Comprende las competencias externas (integración, participación y aprendizaje) e internas (solidaridad, compromiso, respeto, adaptabilidad) que sus estudiantes pueden desarrollar para abordar de mejor manera la GRD y adaptación al $\mathrm{CC}$ (ACC).

Nota: Fuente de la propia investigación. 